\title{
Detection and characterization of rainbow trout antibody against infectious hematopoietic necrosis virus
}

\author{
Sandra S. Ristow ${ }^{1}$, Jeanene de Avila ${ }^{1}$, Scott E. LaPatra ${ }^{2}$, Kathy Lauda ${ }^{2}$ \\ ${ }^{1}$ Department of Animal Sciences, Washington State University, Pullman, Washington 99164-6332, USA \\ ${ }^{2}$ Clear Springs Trout Company, Buhl, Idaho 83316, USA
}

\begin{abstract}
Sera from 143 rainbow trout Oncorhynchus mykiss surviving 1 and 5 exposures to infectious hematopoietic necrosis virus (IHNV) were analyzed for specific antibody against the virus with an enzyme linked immunoassay (ELISA), plaque neutralization test (PNT) and western blot. By the ELISA, $92 \%$ of all survivors demonstrated antibodies against IHNV, while $82 \%$ of them showed neutralizing antibodies against the virus by PNT. A correlation analysis (Kendall's Tau-b) performed on the ELISA values and PNT values indicated the results of the 2 assays correlated $(p<0.05)$. Sera from fish which had survived 1 exposure $(1 \times)$ to IHN had similar ELISA and PNT values compared to fish which had survived 5 exposures, but were rested in pathogen-free water for $80 \mathrm{~d}$ before bleeding $(5 \times R)$. Fish which had survived 5 exposures $(5 \times)$ and bled $20 \mathrm{~d}$ after placement in pathogen-free water had a significantly different distribution of titer values compared to the other 2 groups. Sera from survivors were reacted in a western blot with the 5 IHNV proteins and probed with a monoclonal antibody recognizing trout immunoglobulin. The majority (74/143) of the trout sera gave no reaction in the western blot. In the groups of survivors which gave positive reactions, the proteins most frequently recognized were the viral membrane protein [M1] by $1 \times$ survivors $(9 / 28)$ and the glycoprotein [G] by $5 \times$ survivors (38/82). The group of $5 \times \mathrm{R}$ survivors also recognized $\mathrm{G}(10 / 33)$ most frequently.
\end{abstract}

\section{INTRODUCTION}

Infectious hematopoietic necrosis virus (IHNV) is one of the most important pathogens plaguing the trout industry in the Pacific Northwest of the United States. IHNV has also become a significant problem in salmonids in Japan (Sano 1976) and northeast China (Luqi \& Zhizhuang 1988). Most recently, the virus was detected in Europe (Arkush et al. 1989, HattenbergerBaudouy et al. 1989).

When the virus was first introduced into the Hagerman Valley, Idaho, USA, infectious hematopoietic necrosis (IHN) epizootics were primarily in large trout $(>100 \mathrm{~g})$; however, infections are now detected in all life stages (Busch 1983). Infectious hematopoietic necrosis virus has a wide host range which not only includes rainbow trout Oncorhynchus mykiss, but also encompasses sockeye $O$. nerka, Atlantic Salmo salar and chinook salmon $O$. tshawytcha. The virus has also been isolated from adult coho salmon $O$. kitsutch, which are generally considered to be resistant (LaPatra et al. 1989)

One of the goals of researchers who study IHNV is to prepare an effective economical vaccine which will immunize and protect all susceptible species against the disease. Several vaccines have been developed and tested against the virus, although none of them have been licensed for general use (Leong et al. 1988). The most promising vaccines are the recombinant subunit vaccines containing portions of the outer coat glycoprotein [G] of the virus. It was shown by Leong's laboratory that the $G$ protein of the virus will confer a level of protective immunity when injected into fish (Engelking \& Leong 1989).

Recently, it was documented that trout successfully surviving IHNV have antibodies against the virus that can be detected by a plaque neutralization test (PNT), immunofluorescence and by enzyme-linked immuno- 
sorbent assay [ELISA] (Jorgensen et al. 1991). In the present paper, we show that these antibodies may be detected with a new simplified ELISA technique and also by a modified PNT. We also demonstrate that the serum antibodies detected by these assays can be further characterized by a western blot against the 5 IHNV proteins: L, the polymerase; $G$, the outer coat glycoprotein; $\mathrm{N}$, the nucleoprotein; and $\mathrm{M} 1$ and $\mathrm{M} 2$, membrane proteins.

Our purpose in studying the reactivity pattern of sera using western blots was to derive information about the spectrum of antibodies which may confer survival on animals otherwise susceptible to IHNV infection. These studies provide information on additional immunogens that may potentially enhance the effectiveness of vaccinles.

\section{MATERIALS AND METHODS}

Fish exposures. Six groups of 60 fish $(68 \mathrm{~g}$ mean weight) were obtained from a production lot of rainbow trout that had recently recovered from an IHN epizootic. Estimated cumulative mortality was about $31 \%$ from a starting population of 150000 fish $(40 \mathrm{~g}$ mean weight). Three of the groups were placed in separate live boxes $(91 \mathrm{~cm} \times 91 \mathrm{~cm} \times 102 \mathrm{~cm})$ and held in their original raceway for $4.5 \mathrm{mo}(1 \times$ survivors). The 3 remaining groups were also placed in separate live boxes but were held in another raceway among fish with gross clinical signs of IHN. These 3 groups were moved into 4 different raceways which contained fish with gross clinical signs of IHN over a 4.5 mo period ( $5 \times$ survivors). Each live box group was monitored and fed a dry pelleted diet daily (Clear Springs Trout Co.). Fish in each treatment group were subsequently combined and held in separate $378.5 \mathrm{l}$ fiberglass tanks in pathogen-free water for $20 \mathrm{~d}(1 \times$ and $5 \times$ survivors) or $80 \mathrm{~d}$ ( $5 \times \mathrm{R}$ survivors) before being bled.

Serum samples. Fish bled after being held $20 \mathrm{~d}$ in pathogen-free water included 28 of the $1 \times$ survivors and 82 of the $5 \times$ survivors. An additional 33 of the $5 \times$ survivor fish $(5 \times R)$ were bled $80 \mathrm{~d}$ after removal from the raceways. Individual serum samples were obtained by caudal puncture after euthanizing the fish in a lethal concentration of tricaine methane sulfonate. Blood samples were placed at $4{ }^{\circ} \mathrm{C}$ and allowed to clot overnight. The specimens were centrifuged at $550 \times \mathrm{g}$ and the serum stored at $-75^{\circ} \mathrm{C}$.

Enzyme linked immunoassay (ELISA). The ELISA to detect serum antibody against IHNV was performed according to the general method described by Arkoosh \& Kaattari (1990). Wells of Immulon I microtiter plates were coated with $0.1 \mu \mathrm{g}$ of purified IHNV (isolate 220-90; LaPatra et al. 1991) in a carbonate buffer
(pH 9.6) overnight at $4{ }^{\circ} \mathrm{C}$. Subsequently, the wells were rinsed 5 times with phosphate-buffered saline containing $0.05 \%$ Tween 20 detergent (PBST). Wells were blocked with a $3 \%$ solution of bovine serum albumin (BSA) in PBST for $2 \mathrm{~h}$ at room temperature. Serial dilutions of the trout serum from 1:10 to $1: 5120$ in PBS with $1 \%$ bovine serum albumin were incubated in duplicate on the plates for $16 \mathrm{~h}$ in an incubator at $16^{\circ} \mathrm{C}$. After washing the plates 5 times with PBST, a biotinylated antibody recognizing salmonid immunoglobulin (DeLuca et al. 1983, Gretch et al. 1987) was added and the plates incubated for $1 \mathrm{~h}$. After 5 washes with PBST, a 1:3000 dilution of streptavidin-peroxidase (Zymed, San Francisco, CA, USA) in PBST-1\%BSA was added for $1 \mathrm{~h}$. After 5 more washes with PBST, the peroxidase enzyme substrate, $0.1 \% 5$-amino salicylic acid containing $0.005 \%$ hydrogen peroxide, was added. Plates were read at $490 \mathrm{~nm}$ in a Cambridge plate reader spectrophotometer after $1 \mathrm{~h}$ of development. The anti-IHNV titer of each serum sample was recorded as the reciprocal of the highest dilution of serum which was twice the background control value (Voller et al. 1979).

Plaque neutralization titer (PNT). The PNT procedure for IHNV has been described previously (Hattenberger-Baudouy et al. 1989, Jørgensen et al. 1991). Rainbow trout complement was obtained from specific pathogen-free research fish which were fasted for a minimum of $2 \mathrm{wk}$. Blood was obtained by caudal puncture, pooled, and was allowed to clot at $4{ }^{\circ} \mathrm{C}$ overnight. Serum complement was harvested, aliquoted and frozen at $-75^{\circ} \mathrm{C}$ until needed. Serum samples to be tested were heat-inactivated at $45^{\circ} \mathrm{C}$ for $30 \mathrm{~min}$ to destroy residual complement. A 2 -fold dilution series of trout serum (1:20 to 1:2560) was made in Hanks' balanced salt solution (GIBCO Laboratories, Grand Island, NY, USA) in 96-well round bottom tissue culture plates (Corning Glassworks, Corning, NY). An equal volume of stock IHNV (220-90; LaPatra et al. 1991) (2000 PFU $\mathrm{ml}^{-1}$ ) was added to each well and the plates were incubated for $30 \mathrm{~min}$ at $18^{\circ} \mathrm{C}$ on a rocker platform. An equal volume of complement (1:10 dilution) was added to each well and plates were incubated for an additional $30 \mathrm{~min}$ at $18{ }^{\circ} \mathrm{C}$ on a rocker platform. Samples were plaque assayed in duplicate for each serum dilution being tested on monolayers of Epithelioma papulosum cyprini cells (EPC) (Fijan et al. 1983) in 48-well tissue culture plates (GIBCO Laboratories). Prior to inoculation, the cell culture medium was removed and monolayers were pretreated with $7 \%(\mathrm{w} / \mathrm{v})$ polyethylene glycol (Fisher Chemical, Fairlawn, NJ, USA). Samples being tested were adsorbed $1 \mathrm{~h}$ at $18^{\circ} \mathrm{C}$, the inoculum removed, and cells overlayed with a $1 \%$ methyl cellulose medium (Sigma Chemical Co., St. Louis, MO, USA) (Burke \& Mulcahy 1980). After 6 d incubation at 
$18^{\circ} \mathrm{C}$, cells were fixed with formalin and stained with a $1 \%$ crystal violet solution. Plaques were counted and antibody concentrations reported as the reciprocal of the highest dilution that resulted in a $50 \%$ reduction in the average number of plaques detected in the negative control wells. For each 22 serum samples tested, a positive and negative control were also included.

Western blot. A western blot analysis was performed in order to identify individual virus proteins recognized by serum from survivors. Purified virus (Leong et al. 1981) and prestained molecular weight markers (Amersham Rainbow colored markers) were heated in Laemmli buffer (Laemmli 1970). A sample of $90 \mu \mathrm{g}$ of virus in $200 \mu \mathrm{l}$ of Laemmli buffer was applied to the preparative well of a $10 \%$ SDS-PAGE gel overlayed with a $5 \%$ stacking gel in a miniature protein electrophoresis unit (Mini-Protean II, BioRad, Richmond, CA, USA). Electrophoresis was performed at $200 \mathrm{~V}$ for 45 min. The gel was blotted onto a nitrocellulose sheet in a buffer containing $25 \mathrm{mM}$ Tris and $192 \mathrm{mM}$ glycine containing $10 \%$ methanol (Towbin 1979) for $4 \mathrm{~h}$ at $70 \mathrm{~V}$. The blot was blocked in $3 \%$ gelatin-tris buffered saline for $1 \mathrm{~h}$ and then washed 3 times with TBS for $5 \mathrm{~min}$ and subsequently sandwiched between the 2 halves of an acrylic block system containing 20 sample slots (BioRad MiniProtean Multiscreen, Richmond, CA). Trout serum at a 1:10 dilution was applied to the slots and incubated for $16 \mathrm{~h}$ at $16^{\circ} \mathrm{C}$. After incubation, the blot was rinsed 3 times for $5 \mathrm{~min}$ in TTBS (tris-buffered saline containing $0.05 \%$ Tween 20 as supplied in the BioRad \#170-6464 kit; BioRad, Richmond, CA). Clarified culture fluid from a 2 wk old dying culture of a hybridoma producing an antibody against trout immunoglobulin (1-14; DeLuca et al. 1983) was diluted 1:1 in TTBS and incubated with the blot for $1 \mathrm{~h}$. Following 3 rinses in TTBS, the bands which reacted with the monoclonal antibody were developed with the elements of the kit including a second goat anti-mouse antibody coupled to peroxidase. The substrate supplied with the kit allowed the bands to which the trout antibody attached to be visualized as purple-brown areas on a white background. The sheet was photographed and the positions of the bands were recorded.

Statistical analysis. The distribution of data (observed frequencies) of the titers for the $1 \times, 5 \times$ and $5 \times \mathrm{R}$ survivors were compared in the ELISA and the PNT assay using the chi-square test for heterogeneity (Zar 1974), a test for frequency data analogous to a 1 -way analysis of variance. When the overall test for heterogeneity was found to be significant, pairwise comparisons were made using the same test procedure. Because of the ordinal nature of the data, Kendall's Tau-b (Bishop et al. 1975) was chosen for computing within group correlations for all variables (ELISA and PNT).

\section{RESULTS}

\section{ELISA and PNT}

Results of the ELISA on the 3 treatment groups ( $1 \times$, $5 \times$, and $5 \times \mathrm{R}$ ) revealed that $92 \%$ of the sera tested had antibodies to IHNV (Table 1). Likewise, $82 \%$ of the sera possessed neutralizing antibodies as measured by the PNT (Table 1). The ELISA titer was a highly significant $(p<0.0001)$ predictor of the PNT value with respect to the $1 \times$ and $5 \times$ survivor groups and a significant $(\mathrm{p}<0.05)$ predictor for the $5 \times \mathrm{R}$ survivors (Table 2). When the chi-square test for heterogeneity (Zar 1974) was used to determine differences among frequency distributions of antibody titers for the 3 survivor groups, it was found that the frequency distributions of titers of the $1 \times$ and $5 \times \mathrm{R}$ were not different from one another; however, they were different from the $5 \times$ survivor group (Table 3 ).

\section{Western blots}

When western blots were performed on the serum from survivors from all groups, different reactivity patterns were observed. Fig. 1 is an example of a western

Table 1. Oncorhynchus mykiss. Frequency of antibody titers detected in survivors $(1 \times, 5 \times, 5 \times R)$ of IHNV exposures. (See 'Materials and methods' for classifications of survivors). Titers were determined by an enzyme-linked immunoassay (ELISA) or a modified plaque neutralization test (PNT)

\begin{tabular}{|ccccccc|}
\hline $\begin{array}{c}\text { Antibody } \\
\text { titer }\end{array}$ & $1 \times$ & $5 \times$ & $5 \times \mathrm{R}$ & $1 \times$ & $5 \times$ & $5 \times \mathrm{R}$ \\
\hline 0 & 0 & 5 & 6 & 2 & 13 & 10 \\
10 & 1 & 2 & 0 & 0 & 0 & 0 \\
20 & 2 & 2 & 5 & 5 & 1 & 6 \\
40 & 6 & 6 & 4 & 3 & 7 & 5 \\
80 & 1 & 20 & 5 & 5 & 11 & 6 \\
160 & 4 & 10 & 6 & 8 & 19 & 5 \\
320 & 4 & 19 & 2 & 3 & 14 & 0 \\
640 & 4 & 10 & 3 & 1 & 11 & 1 \\
1280 & 6 & 2 & 2 & 0 & 3 & 0 \\
2560 & 0 & 4 & 0 & 1 & 3 & 0 \\
5120 & 0 & 2 & 0 & 0 & 0 & 0 \\
\hline
\end{tabular}

Table 2. Kendall's Tau-b analysis of correlation was applied to the antibody titers of the $1 \times, 5 \times$ and $5 \times R$ survivors to determine whether the titers determined with the ELISA correlated with the titers found in the PNT assay

\begin{tabular}{|lcr|}
\hline & Kendall Tau-b & p-value \\
\hline $1 \times$ survivors & 0.583 & $<0.0001$ \\
$5 \times$ survivors & 0.558 & $<0.0001$ \\
$5 \times$ R survivors & 0.338 & 0.0107 \\
\hline
\end{tabular}


Table 3. Chi-square test for heterogeneity for the data in Table 1. The significance of comparisons of the antibody titers of the groups of survivors within each assay method is presented. Differences between groups of survivors are significant at the p-value shown

\begin{tabular}{|lcl|}
\hline & Chi-square & p-value \\
\hline ELISA & & \\
$1 \times$ vs $5 \times$ & 24.954 & 0.0054 \\
$1 \times$ vs $5 \times \mathrm{R}$ & 14.249 & 0.0755 \\
$5 \times$ vs $5 \times \mathrm{R}$ & 20.074 & 0.0286 \\
PNT & & \\
$1 \times$ vs $5 \times$ & 15.819 & 0.0450 \\
$1 \times$ vs $5 \times R$ & 10.365 & 0.1688 \\
$5 \times$ vs $5 \times \mathrm{R}$ & 26.134 & 0.0010 \\
\hline
\end{tabular}

blot showing the result from sera of several $5 \times$ and $5 \times R$ survivors, which gave varied responses to the viral proteins. Blotting patterns obtained with fish within a particular surviving treatment group were highly variable. Of the 143 fish, 74 (52\%) showed no response in the blot and the others responded to single viral proteins or to multiple viral proteins (Table 4). The protein most frequently recognized by the fish sera was the viral glycoprotein, $\mathrm{G}(52 / 143$ samples). Within the $1 \times$ survivor group, the most frequently recognized protein was the membrane protein, M1 (9/28); while within the $5 \times$ and $5 \times R$ groups, it was G (38/82 and $10 / 33)$.

\section{DISCUSSION}

Both methods used to analyze the serum from the 3 treatment groups indicated that antibodies to IHNV are present in serum from trout surviving IHN. A previous study (Jørgensen et al. 1991) also showed with ELISA, PNT and immunofluorescence that anti-IHNV antibody could be detected in fish which had survived IHN. Although we did not analyze the serum samples by immunofiuorescence, we did determined our titers by PNT and ELISA. The simplified ELISA does not require that the virus be attached to the immunoplate by an anti-viral antiserum and also utilizes the biotinylated 1-14 antibody and streptavidin peroxidase as detectors (Arkoosh \& Kaattari 1990). Furthermore, because the ELISA significantly correlates with PNT (Table 3), it may be possible to substitute the $18 \mathrm{~h}$ ELISA for the more lengthy PNT whose result requires $6 \mathrm{~d}$ of incubation.

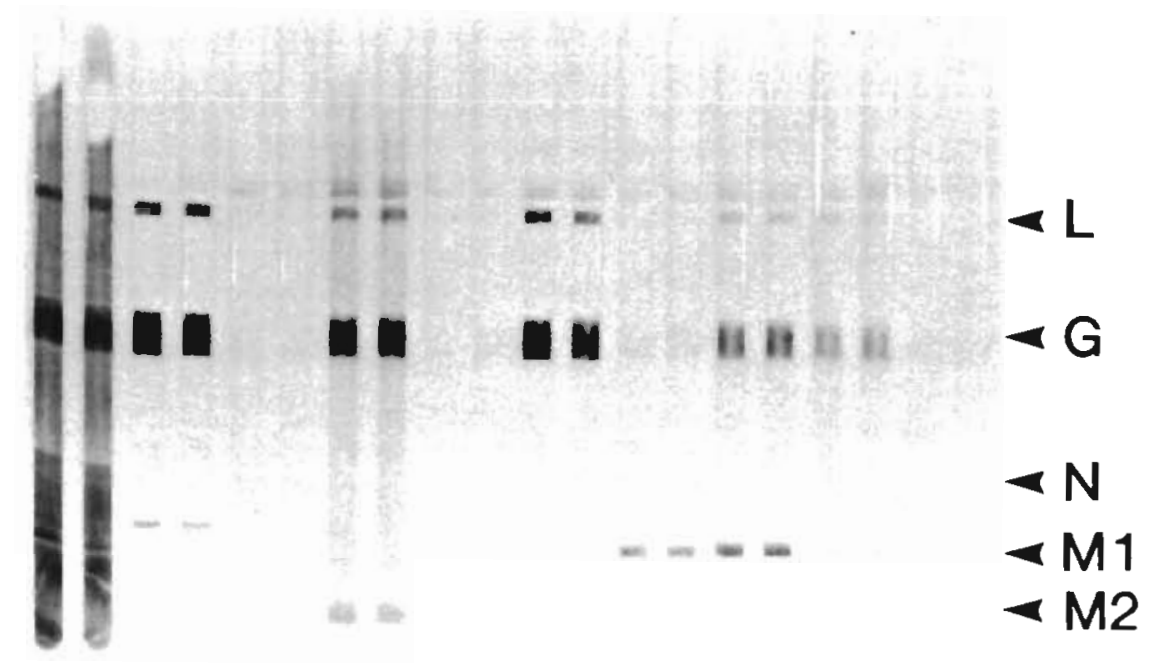

Fig. 1. Oncorhynchus mykiss. Western blot of the sera from $5 \times$ and $5 \times R$ survivor trout run in duplicate. $5 \times$ survivors are found in Lanes 1 to 16 . Lanes 17 to 20 contain samples from $5 \times R$ survivors. Positions of the major viral proteins $L, G, N, M 1$ and $M 2$ are indicated on the right of the figure

Table 4. Oncorhynchus mykiss. Reactions of 143 survivor trout in the western blot. The first number indicates the number of trout within a group which gave a single reaction to a protein, reactions to multiple proteins, or no reaction in the blot. The second number (in parentheses) is the percentage of total survivors $(1 \times, 5 x, 5 \times R)$ that reacted

\begin{tabular}{|c|c|c|c|c|c|c|c|c|c|c|c|c|}
\hline \multirow[t]{2}{*}{ Group } & \multicolumn{5}{|c|}{ No of sera reacting with single viral proteins } & \multicolumn{6}{|c|}{ No. of sera reacting with multiple viral proteins } & \multirow{2}{*}{$\begin{array}{c}\text { No. of sera } \\
\text { with no } \\
\text { response }\end{array}$} \\
\hline & L & $\mathrm{G}$ & $N$ & M1 & M2 & $L, G, M 1, M 2$ & $G, M$ & G.M1 & $N, M 1$ & $L, G$ & $G, N, M 1$ & \\
\hline $1 \times(n=28)$ & $0(0)$ & $0(0)$ & $0(0)$ & $2(7.1)$ & $0(0)$ & $2(7.1)$ & $0(0)$ & $1(3.6)$ & $4(14.3)$ & $2(7.1)$ & $0(0)$ & $17(60.7)$ \\
\hline $5 \times(n=82)$ & $2(2.4)$ & $26(31.7)$ & $1(1.2)$ & $3(3.7)$ & $1(1.0)$ & $0(0)$ & $5(6.1)$ & $1(1.2)$ & $1(1.2)$ & $5(6.1)$ & $1(1.2)$ & $36(43.9)$ \\
\hline $5 \times R(n=33)$ & $0(0)$ & $2(6.1)$ & $2(6.1)$ & $0(0)$ & $o(0)$ & $0(0)$ & $1(3.0)$ & $2(6.1)$ & $0(0)$ & $5(15.2)$ & $0(0)$ & $21(63.6)$ \\
\hline $\operatorname{Sum}(n=143)$ & $2(1.4)$ & $28(19.6)$ & $3(2.1)$ & $5(3.5)$ & $1(0.7)$ & $2(1.4)$ & $6(4.2)$ & $4(2.8)$ & $5(3.5)$ & $12(8.4)$ & $1(0.7)$ & $74(51.7)$ \\
\hline
\end{tabular}


An interesting result indicated by the PNT values was that $5 \times$ survivors had a significantly different distribution of antibody titers to IHNV from those of the $1 \times$ or $5 \times \mathrm{R}$ treatment groups. It is also of interest that fish which had been exposed one time to IHNV 5 mo earlier $(1 \times)$ had the same distribution of antibody titers as fish which had been exposed to IHNV 5 times and rested $80 \mathrm{~d}(5 \times \mathrm{R})$ before bleeding. It is tempting to speculate that for the fish to maintain the distribution of antibody titers exhibited by the $5 \times$ survivors they must be continually exposed to IHNV. The majority of sera tested demonstrated positive antibody titers to IHNV in the ELISA (92\%) and PNT (82\%), unlike the previous study (Jørgensen et al. 1991) where only $45 \%(9 / 20)$ of the fish tested exhibited positive PNT and ELISA titers. However, some of the fish used in this study were exposed to IHNV 5 times.

Other investigators have noted the relatively restricted humoral response of the salmonid immune system to various antigens (Cossarini-Dunier 1986, Espelid et al. 1987, Killie et al. 1991, Mourich \& Leong 1991, Voss et al. 1978). For example, polyclonal antibody of Atlantic salmon Salmo salar against Vibrio salmonicida was able to significantly compete with only 1 of 13 mouse monoclonal antibodies in an ELISA against the bacterium (Espelid 1987). Even after a secondary response, the relative affinity of coho salmon anti-fluorescyl antibodies for that antigen remained the same (Voss et al. 1978). Mourich \& Leong (1991) noted that trout immunized with IHNV in Freund's complete adjuvant only responded to 2 of the 5 virus proteins ( $G$ and $M 1$ ) on a western blot, and to only 1 of the trpE fusion proteins which encoded a particular region of the glycoprotein of the virus in their western blots.

The fact that fewer than $50 \%$ of all fish in this study responded in the western blot is troublesome. In the western blot, those fish which do respond to the virus produce antibodies which variously recognize the linear epitopes of all 5 viral proteins, either singly or in various combinations. One might speculate that in the ELISA, in which the virus is bound to the plastic plate, viral proteins most prominently presented to the fluid phase would be the outer coat glycoprotein and possibly the 2 membrane proteins, M1 and M2 (in which the glycoprotein is imbedded). In the ELISA, therefore, anti-glycoprotein antibodies and anti-membrane protein antibodies would be the predominating species measured. Likewise, because the PNT assay measures neutralizing antibody to the glycoprotein, the result in the PNT assay is most likely to correlate with the result in the ELISA, and not necessarily to the result in the western blot which measures responses to the 5 viral proteins presented in denatured form on nitrocellulose.

Fish serum with high antibody titers detected by
PNT or ELISA did not necessarily have a positive western blot to IHNV structural proteins. A possible explanation for a negative western blot is that the immune response of trout involved tertiary epitopes of the viral proteins, which may have been destroyed when they were subjected to the denaturing conditions of SDS-PAGE. It is speculated that proteins bound to nitrocellulose are presented to the blotting antibodies in a relaxed conformation, thereby eliminating most of the tertiary structure and allowing the antibodies to attach to only the linear epitopes. It is possible that many trout which possessed significant titers of neutralizing antibody were actually responding to tertiary epitopes which were no longer recognizable when the glycoprotein was blotted. Another alternative explanation is that the 1-14 monoclonal antibody (DeLuca et al. 1983) did not bind to the denatured conformation of the trout antibodies as they were presented in the western blot. In future experiments, the presence of antibody to tertiary epitopes should be measureable by immunoprecipitation techniques such as using ${ }^{35} \mathrm{~S}$ methionine labeled viral proteins in which the proteins retain some of their 3-dimensional structure (Ristow \& Arnzen de Avila 1991).

The western blot results indicate that $9 / 28$ sera from $1 \times$ survivor fish were positive to protein $\mathrm{M} 1$, while $5 / 28$ responded to $G$. Of those $1 \times$ responders, $4 / 5$ which reacted to $\mathrm{G}$ also reacted with $\mathrm{M} 1$. It is tempting to speculate that M1 added to the recombinant vaccines might make the vaccines more effective, but this will have to be thoroughly tested in experimental trials. It was important to note that although $74 / 143$ fish gave no response in the blots, the most frequent immunogen recognized in the blots was $G(52 / 143)$, the protein shown to be protective against IHNV in different salmonid species (Engelking \& Leong 1989).

Acknowledgements. The authors acknowledge the valuable assistance of Jim Parsons, Jerry Jones, David White, Sunshine Walker and Terry Turner at Clear Springs Trout. S. Ristow acknowledges Mark Evans and Thomas Bogyo of the WSU Program in Statistics for statistical analysis. This is scientific paper 8063 from the College of Agriculture and Home Economics Research Center of Washington State University. This work was supported by grants 90-38500-5025 \& 91-38500-6078 from the USDA to the Western Regional Aquaculture Consortium.

\section{LITERATURE CITED}

Arkoosh, M., Kaattari, S. L. (1990). Quantitation of fish antibody to a specific antigen by an enzyme linked immunosorbent assay (ELISA). In: Stolen, J. S., Fletcher, T C., Anderson, D. P., Roberson, B. S., van Muiswinkel, W. B. (eds.) Techniques in fish immunology SOS Publications, Fairhaven, NJ, p. 15-24

Arkush, K. D., Bovo, G., de Kinkelin, P., Winton, J. R., Wingfield W. H., Hedrick, R. P. (1989). Biochemical and 
antigenic properties of the first isolates of infectious hematopoietic necrosis virus from salmonid fish in Europe. J. aquat. Anim. Health 1: 148-153

Bishop, Y M. M., Feinberg, S. E., Holland P. W. (1975). Discrete multivariate analysis: theory and practice. MIT Press, Cambridge, MA

Burke, J. A., Mulcahy D. (1980). Plaquing procedure for infectious hematopoietic necrosis virus. Appl. environ. Microbiol. 39: 372-376

Busch, R. A. (1983). Viral disease considerations in the commercial trout industry in Idaho. In: Leong, J. C., Barilla $T$ Y. (eds.) Workshop on viral diseases of salmonid fishes in the Columbia River Basin. Bonneville Power Administration, Special Publication, Portland, OR, p. 84-100

Cossarini-Dunier, M. (1986). Secondary response of rainbow trout (Salmo gairdneri Richardson) to DNP-hemocyanin and Yersinia ruckeri. Aquaculture 52: 81-86

DeLuca, D., Wilson, M., Warr, G. W. (1983). Lymphocyte heterogeneity in the trout, Salmo gairdneri, defined with monoclonal antibodies to IgM. Eur J. Immunol. 13: 546-551

Engelking, H. M., Leong, J. C. (1989). The glycoprotein of infectious hematopoietic necrosis virus elicits neutralizing antibody and protective responses. Virus Res.13: 213-230

Espelid, S., Hjelmeland, K., Jørgensen T (1987). The specificity of the Atlantic salmon antibodies made against the fish pathogen Vibrio salmonicida, establishing the surface protein VS-P1 as the dominating antigen. Dev. comp. Immunol. 11, 529-537

Fijan, N., Salimanovic, D., Bearzotti, M., Muzinic, D., Zwillenberg, L.O., Chilmonczyk, S., Vautherot, J.F., de Kinkelin. P. (1983). Some properties of the Epithelioma papulosum cyprini (EPC) cell line from carp Cyprinus carpio. Ann. de Virol. (Inst. Pasteur) 134E: 207-220

Gretch, D. R., Suter, M., Stinski, M. F. (1987). The use of biotinylated monoclonal antibodies and streptavidin affinity chromatography to isolate herpesvirus hydrophobic proteins or glycoproteins. Analyt. Biochem. 163: 270-277

Hattenberger-Baudouy, A.-M., Danton, M., Merle, G., Torchy, C., de Kinkelin, P. (1989). Serological evidence of infectious hematopoietic necrosis in rainbow trout from a French outbreak of disease. J. aquat. Anim. Health 1: $126-134$

Jørgensen, P. E. V., Olesen, N. J., Lorenzen, N., Winton, J. R., Ristow S. S. (1991). Infectious hematopoietic necrosis (IHN) and viral hemorrhagic septicemia (VHS): detection of trout antibodies to the causative viruses by means of plaque neutralization, immunofluorescence, and enzymelinked immunosorbent assay. J. aquat. Anim. Health 3: 100-108

Killie, J.E., Espelid, S., Jorgensen, T (1991). The humoral immune response in Allantic salmon (Salmo salar L.) against

Responsible Subject Editor: F. M. Hetrick, College Park, Maryland, USA the hapten carrier antigen NIP-LPH. The effect of determininant (NIP) density and the isotype profile of anti-NIP antibodies. Fish and Shellfish Immunol. 1: 33-46

Laemmli, U. K. (1970). Cleavage of structural proteins during the assembly of the head of bacteriophage T4. Nature 227 : $680-685$

LaPatra, S. E., Fryer, J L., Wingfield, W. H., Hedrick, R. P. (1989). Infectious hematopoietic necrosis virus in coho salmon Oncorhynchus kisutch. J. aquat. Anim. Health 1: $277-280$

LaPatra, S. E., Lauda, K. A., Morton, A. W. (1991). Antigenic and virulence comparison of eight isolates of infectious hematopoietic necrosis virus from the Hagerman Valley, Idaho, USA. In: Fryer, J. L. (ed.) Proceedings of the Second International Symposium on Viruses of Lower Vertebrates. Oregon State Univ., Corvallis, p. 125-129

Leong, J. C., Fryer, J. L., Winton, J R. (1988). Vaccination against infectious hematopoietic necrosis In: Ellis, A. E. (ed) Fish varcination Arademir Press, San Diegn p. $193-203$

Leong, J. C., Hsu, Y.-L., Engelking, H. M., Mulcahy, D. (1981). Strains of infectious hematopoietic necrosis (IHN) virus may be identified by structural protein differences. Dev. biol. Standard. 49: 43-55

Luqi, N., Zhizhuang, Z. (1988). The epidemiology of IHN and IPN of rainbow trout in northeast China. J. Fish. China 12: 327-332

Mourich, D. V., Leong, J. C. (1991). Mapping of the immunogenic regions of the IHNV glycoprotein in rainbow trout and mice. In: Fryer, J. L. (ed.) Proceedings of the International Symposium on Viruses of Lower Vertebrates. Oregon State Univ., Corvallis p. 93-100

Ristow, S. S., Arnzen de Avila, J. (1991). Monoclonal antibodies to the glycoprotein and nucleoprotein of infectious hematopoietic necrosis virus (IHNV) reveal differences among isolates of the virus by fluorescence, neutralization and electrophoresis. Dis. aquat. Org. 11: 105-115

Sano, T. (1976). Viral diseases of cultured fishes in Japan. Fish Pathol. 10: 221-226

Towbin, H. (1979). Electrophoretic transfer of proteins from polyacrylamide gels to nitrocellulose: procedure and some applications. Proc. natl. Acad. Sci. USA 76: 4350-4354

Voss, E. W., Groberg, W. J., Fryer, J. L. (1978). Binding affinity of tetrameric coho salmon Ig antihapten antibodies. Immunochem. 15: 459-464

Voller, A., Bidwell, D. E., Bartlett, A. (1979). The enzyme linked immunosorbent assay (ELISA). A guide with abstracts of microplate applications. Dynatech Laboratories, Alexandria, VA

Zar, J. H. (1974). Biostatistical analysis. Prentice-Hall, Inc., Englewood Cliffs, NJ

Manuscript first received: July 22, 1992

Revised version accepted: October 19, 1992 